\title{
Sistem Informasi Lembaga Kursus Private Bahasa Inggris Berbasis Website
}

\section{Yogiek Indra Kurniawan ${ }^{* 1}$, Riski Agung Putro Laksono ${ }^{2}$, Widiyarti Endang Saputri ${ }^{3}$, Danindya Puput Muliana Putri ${ }^{4}$, Arkham Zahri Rakhman ${ }^{5}$}

\author{
${ }^{1}$ Informatika, Fakultas Teknik, Universitas Jenderal Soedirman, Indonesia \\ 2,3,4 Informatika, Fakultas Komunikasi dan Informatika, Universitas Muhammadiyah Surakarta, \\ Indonesia \\ ${ }^{5}$ Teknik Informatika, Institut Teknologi Sumatera, Indonesia \\ Email: ${ }^{1}$ yogiek@unsoed.ac.id
}

\begin{abstract}
Abstrak
Bimbingan belajar English Home Soloraya (EHS) adalah sebuah lembaga pembelajaran konsep homeschooling, yakni para pengajar yang mendatangi rumah para murid untuk bimbingan. EHS memiliki beberapa kendala dalam proses bisnisnya, salah satunya dalam bidang administrasi. Sebelumnya, pendataan murid, pengajar, materi masih dilakukan secara manual. Penjadwalan bimbingan yang sering berubah tanpa konfirmasi kepada pengelola EHS juga telah mempersulit untuk merekapitulasi kehadiran murid dan kerja para pengajar. Bukti kehadiran selama ini digunakan sebagai sumber informasi kedua bagi orangtua untuk memantau proses bimbingan anaknya juga bagi pengelola untuk memantau kinerja para pengajar. Tujuan kegiatan ini adalah untuk membangun sistem informasi untuk lembaga kursus private bahasa inggris berbasis website. Metode yang digunakan yaitu wawancara, metode observasi, serta metode pustaka. Pada sistem informasi berbasis website ini terdapat beberapa menu yang dapat memudahkan pengelola (administrator) untuk mengolah data murid baru, data pengajar, data pre-post test, data kehadiran dan data pembayaran. Website ini dapat membantu pihak EHS untuk selangkah lebih maju dalam penyampaian informasi serta dapat memudahkan mengelola informasi murid dan informasi kegiatan bimbingan agar bisa diakses oleh orangtua murid.
\end{abstract}

Kata kunci: lembaga kursus, sistem informasi, website.

\section{Website-Based Information System for Private English Course}

\begin{abstract}
Tutoring English Home Soloraya (EHS) is a learning institution for the concept of homeschooling, where teachers come to the homes of students for guidance. EHS has several obstacles in its business processes, one of which is in the field of administration. Previously, data collection on students, teachers, and materials was still done manually. The scheduling of tutoring that frequently changes without confirmation to EHS administrators has also made it difficult to recapitulate student attendance and teacher work. Evidence of attendance has been used as a second source of information for parents to monitor their child's mentoring process as well as for managers to monitor the performance of teachers. The purpose of this activity is to build an information system for website-based private English course institutions. The methods used are interviews, observation methods, and library methods. In this website-based information system, several menus can make it easier for administrators to process new student data, teacher data, pre-post test data, attendance data, and payment data. This website can help EHS to be one step ahead in delivering information and can make it easier to manage student information and information on guidance activities so that it can be accessed by parents.
\end{abstract}

Keywords: course institute, information systems, website

\section{PENDAHULUAN}

Profesionalisme sangat dibutuhkan dalam pelaksanaan segala pekerjaan demi terciptanya efektivitas kerja, pengembangan mutu, kinerja yang maksimal dan efisiensi waktu. Dengan adanya sistem yang terkomputerisasi 
semua pekerjaan dapat di lakukan lebih mudah serta penyajian informasi juga cepat tanpa adanya redudansi. Berdasarkan survei yang telah kami lakukan di EHS, mereka masih menggunakan metode pencatatan data pondok secara manual dengan Microsoft Office Excel dan Microsoft Office Word.

Begitu juga pengarsipan manual untuk bukti kehadiran untuk tiap murid masih menggunakan kertas, hal ini sangat berpengaruh dengan pengalokasian jumlah kertas mengingat tiap tutor harus membawa sejumlah arsip bukti kehadiran, belum lagi jika arsipnya tertinggal maka akan mengambil kertas baru dan menambah tumpukan arsip lagi di EHS. Semakin banyak data yang di cetak semakin banyak memakan tempat, pencarian data pun menjadi sangat lama karena pendataan secara komputerisasi tidak dimanfaatkan secara maksimal. Selain itu, pengaksesan soal untuk pre-post test yang dilakukan dalam kurun waktu tertentu masih harus dilakukan secara manual. Tiap tutor harus menghubungi pemilik EHS untuk meminta data soal. Hal tersebut membuat kurangnya efektivitas dalam pengiriman soal diakibatkan jadwal pemilik EHS yang tidak tentu sehingga susah untuk bertemu guna meminta soal.

Beberapa penelitian telah memperlihatkan bahwa aplikasi berbasis komputer dapat diaplikasikan untuk membantu berbagai aspek dalam kehidupan manusia[1], [2]. Lebih khususnya, aplikasi berbasis komputer dapat membantu dalam dunia pendidikan[3]-[7]. Selain itu, aplikasi komputer berbasis website telah terbukti dapat membantu perusahaan untuk menjadi lebih efektif dan efisien[8]-[11]. Pengembangan aplikasi website yang tepat dapat juga membantu pegawai menjadi lebih mudah dalam mengelola pekerjaannya[12].

Guna meningkatkan kinerja dan pelayanan pengolahan informasi murid, tutor, bukti kehadiran tiap murid serta soal pre-post test diperlukan suatu sistem yang mampu mengolah data secara cepat dan mudah, selain itu diperlukan juga sistem yang mampu menampilkan seluruh informasi yang dibutuhkan secara cepat dan akurat. Kebutuhan informasi yang sangat kompleks memerlukan suatu sistem informasi yang mampu menangani kebutuhan tersebut sekaligus[13]. Penggunaan sistem informasi juga dapat membantu sebuah perusahaan untuk mengambil keputusan secara cepat dalam rangka meningkatkan kinerja perusahaannya[14], [15].

Oleh karena itu untuk meningkatkan efisiensi waktu dan efektivitas kerja terkait pengaksesan bukti kehadiran dan soal pre-post test, dibuatlah sebuah sistem informasi berbasis website guna pengolahan kebutuhan informasi pada EHS.

\section{METODE PENELITIAN}

Metode penelitian yang digunakan pada penelitian ini antara lain :

\subsection{Metode Pengumpulan Data}

Terdapat beberapa cara yang dilakukan dalam pengumpulan data ini, antara lain :

a. Metode Wawancara atau Interview. Metode wawancara atau Interview adalah sebuah metode pengumpulan data/informasi dengan cara mencari informasi secara langsung dari pihak yang bersangkutan sebagai narasumber. Kemudian menampung semua informasi yang diberikan oleh narasumber sebagai sebuah data informasi.

b. Metode Observasi. Metode Observasi adalah sebuah metode pengumpulan data dengan cara mengamati langsung objek yang akan diteliti serta mencari tahu informasi yang sudah ada sebelumnya.

c. Metode Pustaka. Metode Pustaka adalah sebuah metode pengumpulan data dengan mencari referensi atau teori yang diperlukan, baik melalui buku, internet maupun data-data tertulis atau dokumen dari pihak yang bersangkutan.

\subsection{Metode Pengembangan Sistem}

Terdapat beberapa langkah dalam pengembangan sistem ini, yaitu :

a. Tahap Perencanaan Website

Website ini dibuat menggunakan beberapa bahasa dan plugin yakni MySQL, PHP, Bootstrap, JQuery Data-Table Server Side, JQuery Date-Picker, Sublime Text Editor. Dengan menggunakan bantuan program tersebut diharapkan Website EHS ini dapat digunakan untuk memaksimalkan waktu dalam proses input data murid maupun pengajar baru dan penyajian informasi kegiatan belajar di dalamnya. Website EHS juga dibuat dengan beberapa fungsi seperti mengakses pre-post test yang dilakukan secara berkala, melihat bukti kehadiran pembelajaran, notifikasi jika belum melakukan pembayaran, menyediakan informasi terbaru dan berita tentang murid, pengajar lembaga tersebut.

b. Tahap desain

Pada tahap ini, dibuat beberapa macam desain yang menggambarkan sistem, yaitu use case diagram dan Entity Relationship Diagram. Terdapat 3 buah usecase sesuai dengan actor dari aplikasi yang akan 
dibangun. Use case yang pertama adalah use case diagram untuk admin yang dapat ditunjukkan oleh gambar 1.

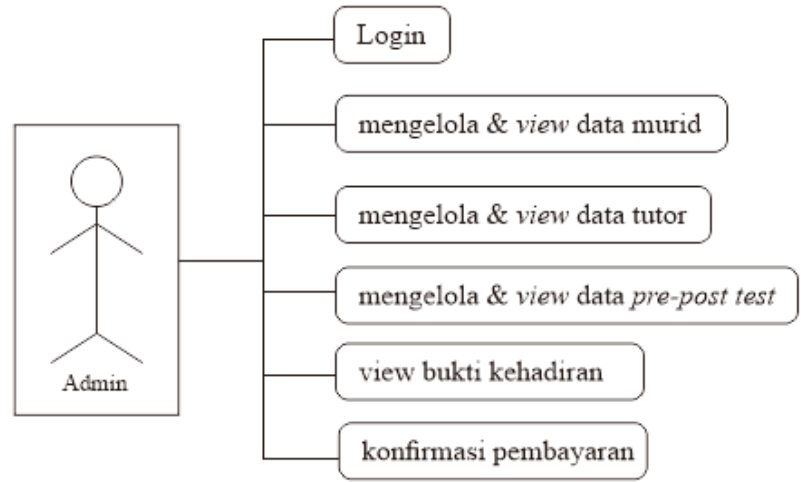

Gambar 1. Usecase diagram admin

Admin sebagai aktor dapat melakukan kegiatan yang berhubungan dengan pengelolaan Website EHS. Use case yang kedua yaitu use case diagram user murid yang dapat ditunjukkan oleh gambar 2 serta yang terakhir adalah use case diagram user tutor yang dapat ditunjukkan oleh gambar 3 .

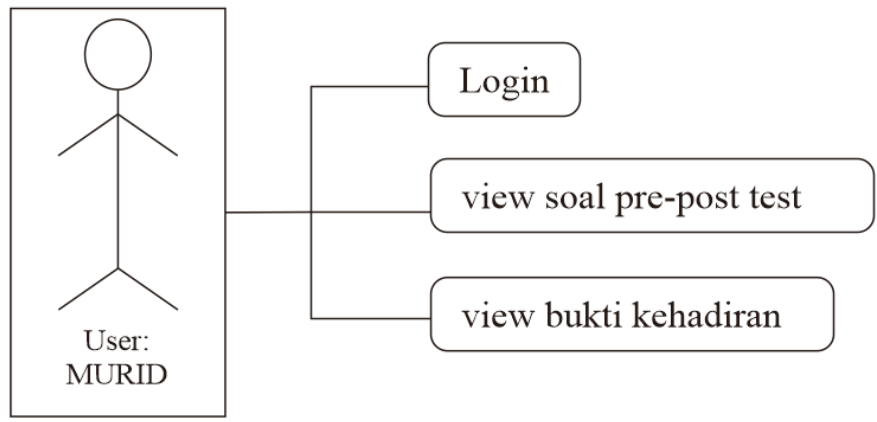

Gambar 2. Usecase diagram user murid

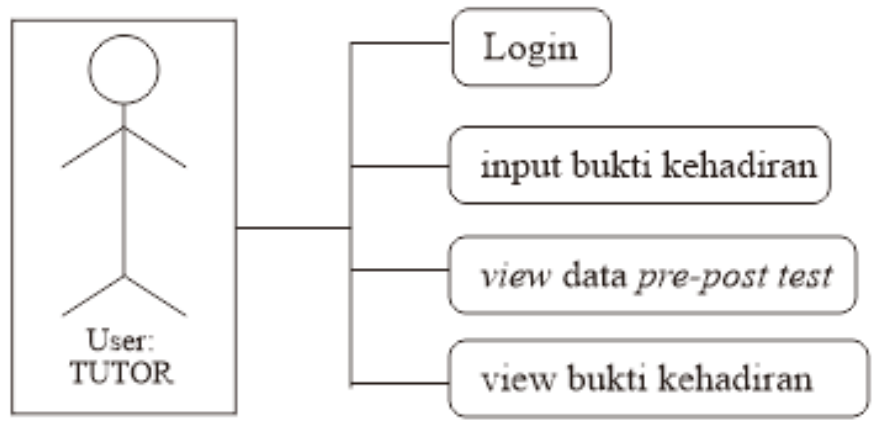

Gambar 3. Usecase diagram user tutor

User sebagai aktor dapat melakukan kegiatan seperti melihat berita, melihat galeri, melihat info, melihat pengajar, melihat album, melihat mahasanri baru dan meihat mata kuliah.

c. Tahap implementasi dan pembuatan sistem

Tahap implementasi adalah tahap untuk menerapkan requirement dari pihak EHS yang dalam hal ini langsung kepada pendirinya. Pembuatan website dilakukan dengan menitikberatkan pada requirement pihak yang bersangkutan. Pemberian informasi EHS yang sebelumnya dilakukan secara manual diubah ke sebuah website dengan memanfaatkan kode program yang tersedia. Kode program untuk input data menggunakan PHP, Javascript, dan JQuery Data Table, JQuery Date-Picker dan Bootstrap untuk 
menampilkan data, untuk pembagian pola menggunakan perhitungan logika yang sebelumya sudah tersedia kemudian diubah kedalam kode program PHP.

d. Implementasi dan pengujian

Pada tahap ini terdapat proses uji coba website dalam beberapa cara yakni input data murid yang akan ditampilkan di website, pengujian dengan mengelola data murid lama maupun baru oleh admin, input data pengajar. Pengujian pertama dilakukan untuk mengetahui apakah admin sudah berhasil login, input, delete dan update data murid dan pengajar. Pengujian kedua dilakukan untuk mengetahui apakah murid berhasil login dan mengakses soal pre-post test yang diunggah oleh pengajar. Pengujian ketiga dilakukan untuk mengetahui apakah admin berhasil login, input, update, dan delete soal pre-post test juga bukti kehadiran saat pembelajarannya. Pengujian keempat dilakukan untuk mengetahui apakah admin berhasil melakukan view bukti kehadiran yang diunggah pengajar setelah kegiatan pembelajaran. Pengujian keempat dilakukan untuk mengetahui apakah admin berhasil melakukan update dan delete pada pembayaran. Pengujian kelima dilakukan apakah murid berhasil mengakses bukti kehadiran dan mendapatkan notifikasi jika belum melakukan pembayaran. Pengujian keenam dilakukan apakah semua hasil input, update, delete data dapat ditampilkan pada website, hal ini dilakukan untuk memastikan jika masih terdapat bug didalam website. Selain itu dilakukan pengujian pada database untuk mengetahui sudah berfungsi dengan semestinya. Dengan adanya serangkaian ujicoba ini, akan dapat diketahui bagian mana didalam website yang masih harus diperbaiki sebelum ke tahap selanjutnya. Hal ini sangat penting dalam mengukur keakuratan website serta mencari tahu letak kekurangan dari website.

\section{HASIL DAN PEMBAHASAN}

Dalam bab ini dibahas mengenai hasil implementasi dari Website EHS yang telah selesai dirancang dan dibuat. Website ini menyimpan seluruh data murid, pengajar, soal pre-post test serta informasi profil EHS yang akan diolah menjadi informasi dan ditampilkan pada Website EHS untuk bisa diakses masyarakat. Semua data yang telah dimasukkan tersimpan dalam database untuk dikelola oleh admin. Implementasi website sebagai berikut:

\subsection{Halaman Awal}

Halaman awal adalah halaman yang pertama kali tampil ketika web di akses. Halaman yang tersedia terdiri dari halaman home, about, vision \& mission, team, portofolio, contact dan login. Tampilan halaman awal dapat ditunjukkan oleh gambar 4 .

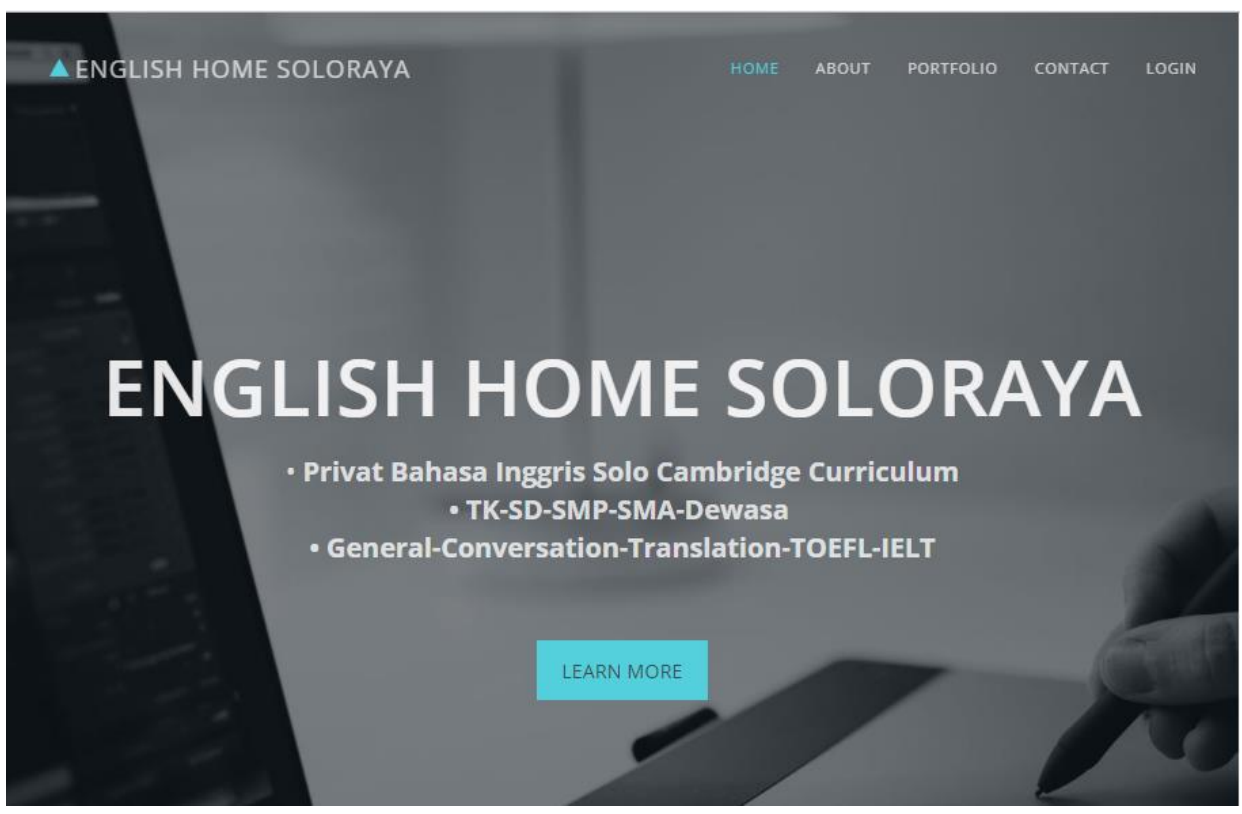

Gambar 4. Tampilan Halaman Awal 


\subsection{Halaman About}

Halaman about adalah halaman yang memuat tentang penjelasan singkat tentang English Home Solo beserta visi dan misi. Tampilan halaman About dapat ditunjukkan oleh gambar 5.

\subsection{Halaman Awal Admin}

Halaman awal (home admin) adalah halaman yang pertama kali muncul setelah login diverifikasi, semua user akan disajikan tampilan nama admin yang saat itu login dan seluruh menu administrator yang terdiri dari menu students, tutor, pre-post test, attendance, payment. Tampilan halaman awal ada pada Gambar 6.

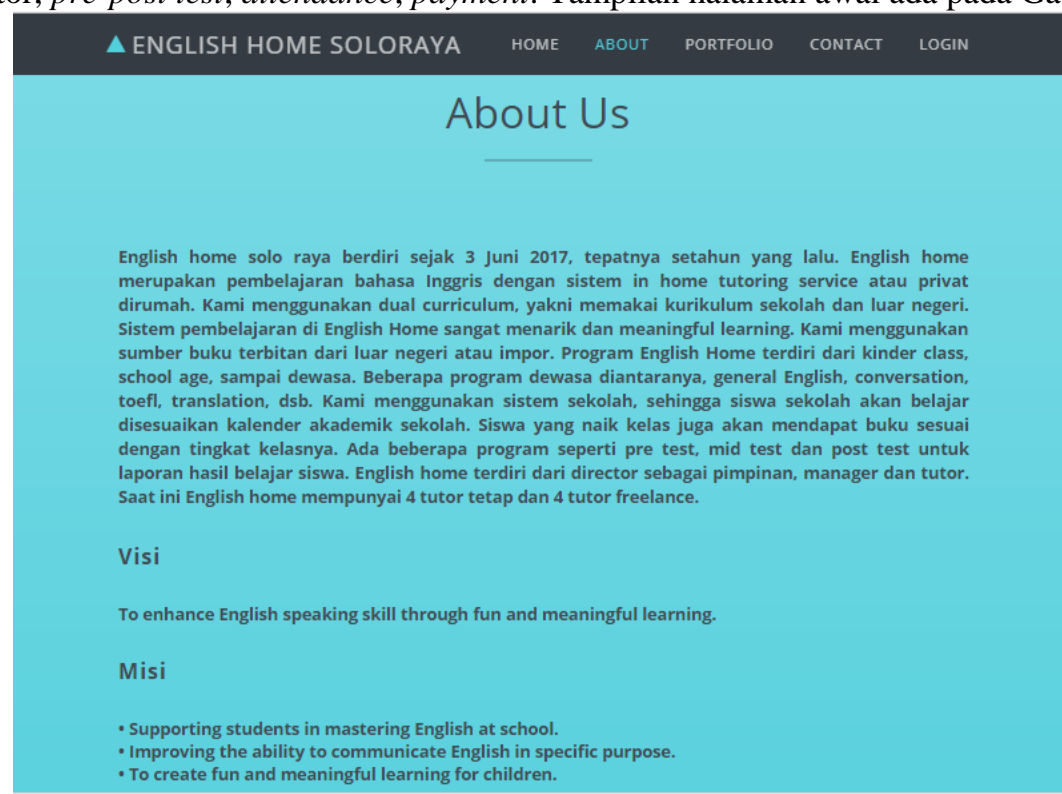

Gambar 5. Halaman about

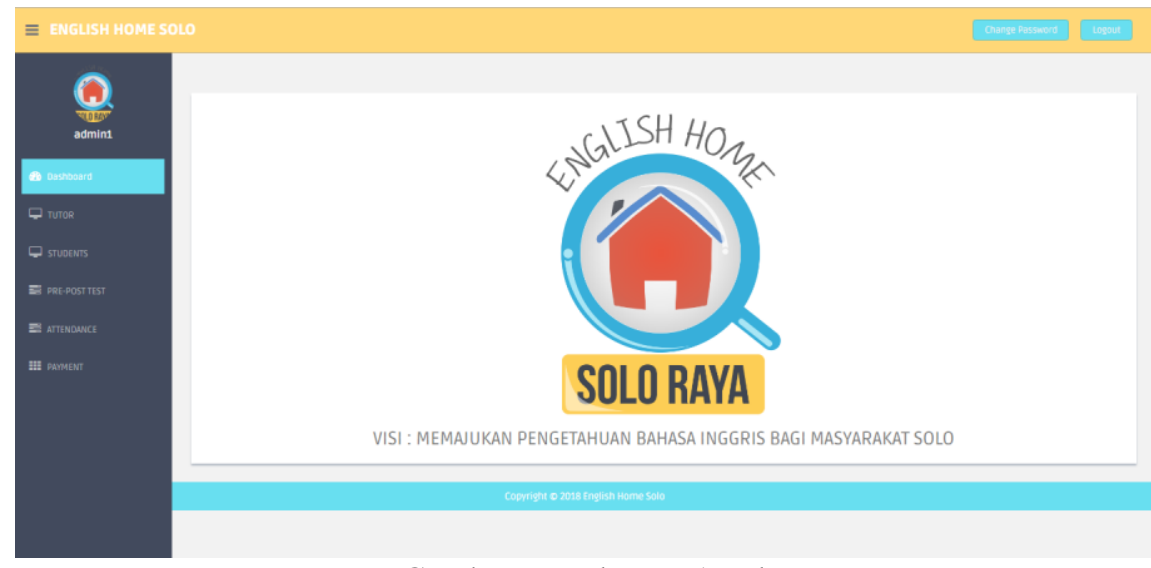

Gambar 6. Halaman Awal 


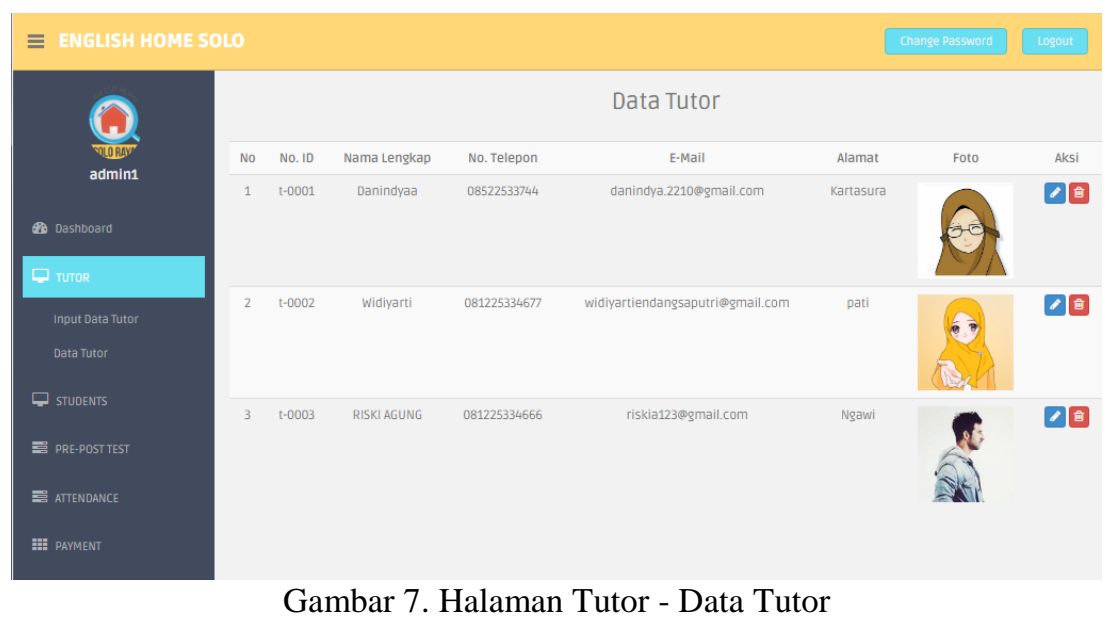

\subsection{Halaman Data Tutor}

Halaman data tutor adalah halaman yang memuat informasi dan mengelola semua data tutor yang mengajar di EHS. Tampilan halaman data tutor ada pada Gambar 7. Di dalam halaman tutor, terdapat menu input data tutor, ubah data tutor dan hapus data tutor.

\subsection{Halaman Data Murid}

Halaman data Murid adalah halaman yang memuat informasi dan mengelola semua data murid di EHS. Tampilan halaman data murid dapat ditunjukkan oleh Gambar 8. Pada halaman data murid, terdapat menu untuk input data murid, ubah data murid serta hapus data murid.

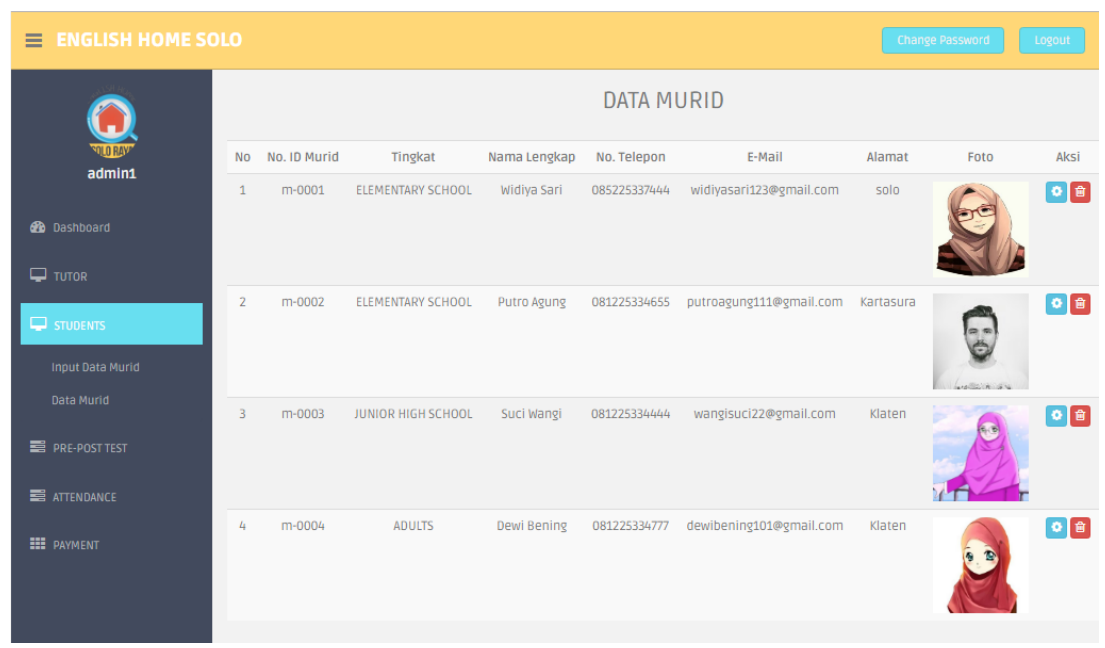

Gambar 8. Halaman Student - Data Murid

\subsection{Halaman Pre-Test dan Post-Test}

Halaman Data Pre-Test dan Post-Test adalah halaman yang digunakan untuk melihat dan membuka latihan soal yang sudah di masukkan. Tampilan data Pre-Test dan Post-Test dapat ditunjukkan oleh gambar 9. Pada halaman ini terdapat menu untuk input data, ubah, maupun hapus data. 


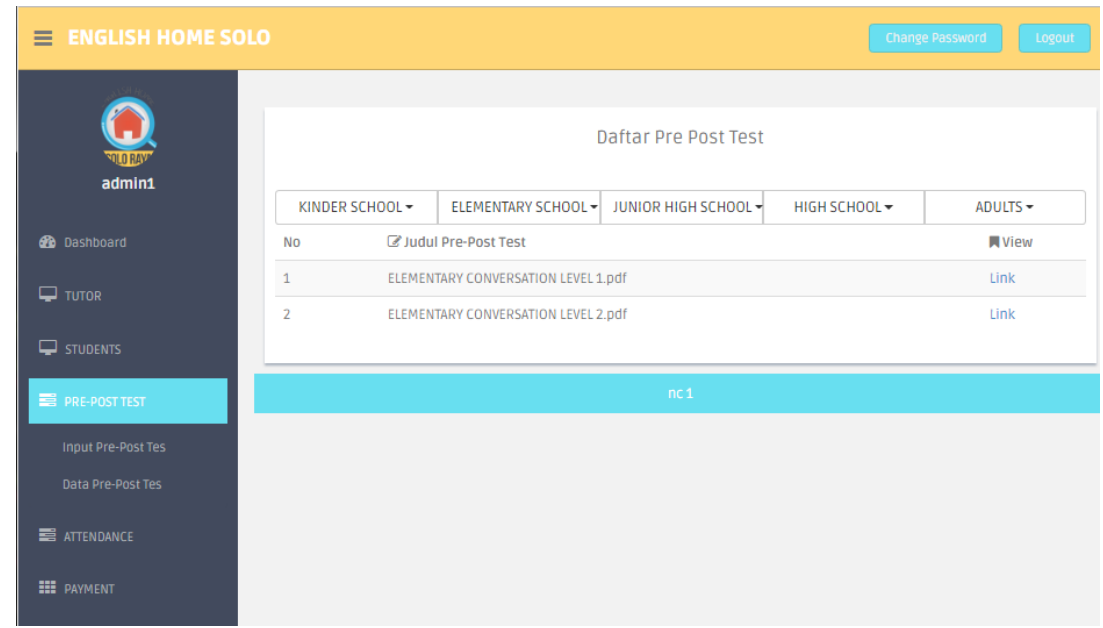

Gambar 9. Halaman Data Pre-post Test

\subsection{Halaman Attendance}

Halaman Attendance adalah halaman yang digunakan untuk melihat data kehadiran murid yang sudah melakukan bimbingan belajar. Tampilan halaman Attendance ada pada Gambar 10.

\subsection{Halaman Payment}

Halaman Payment adalah halaman yang berisi data dan konfirmasi pembayaran yang suda dilakukan oleh murid. Tampilan halaman Payment dapat ditunjukkan oleh gambar 11.

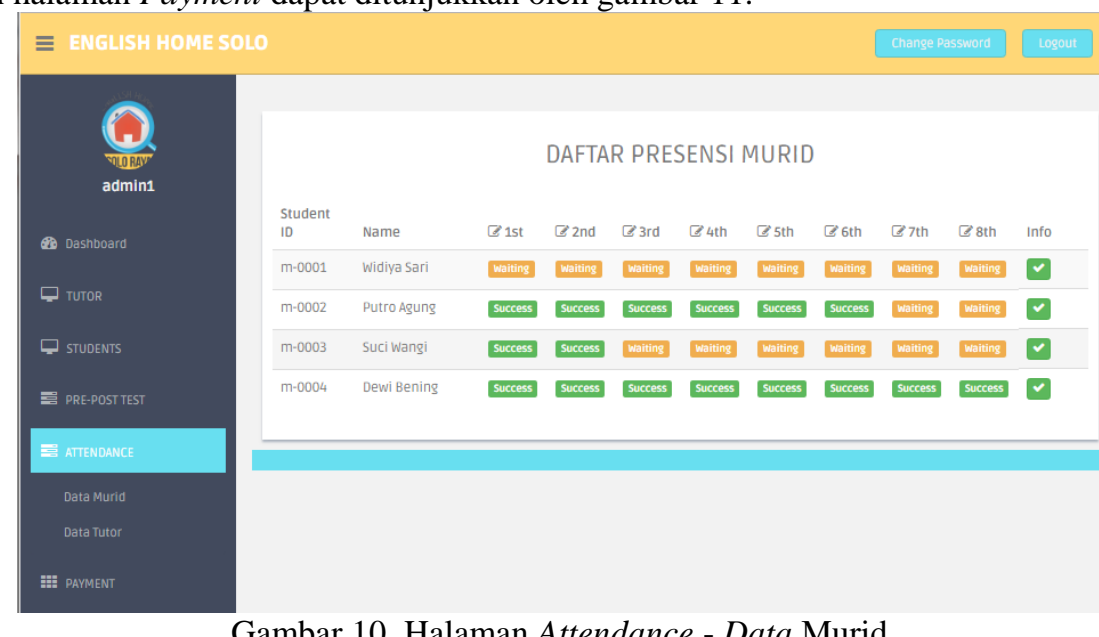

Gambar 10. Halaman Attendance - Data Murid

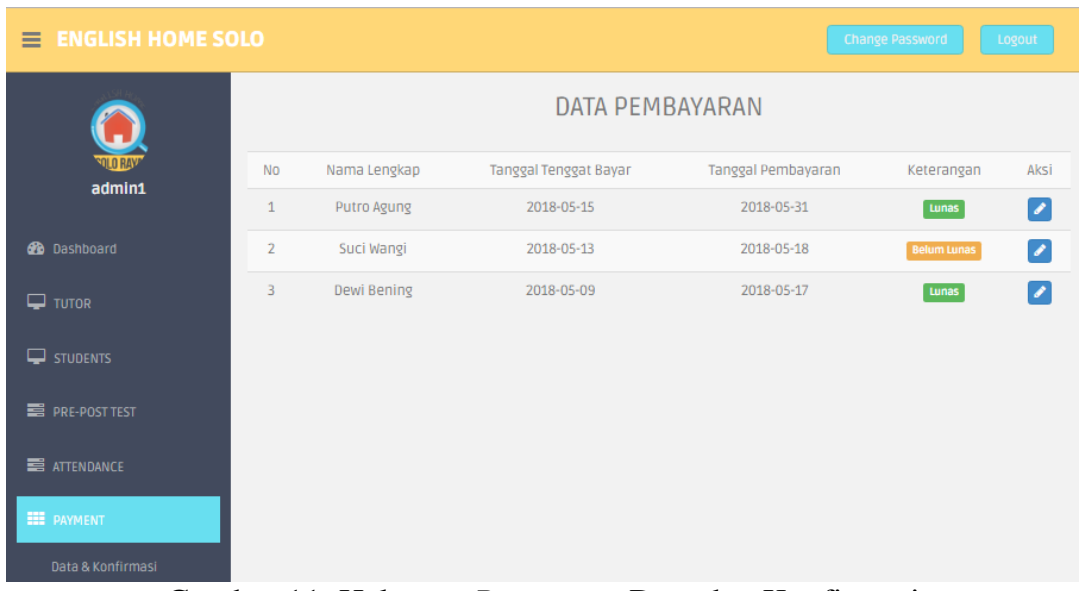

Gambar 11. Halaman Payment - Data dan Konfirmasi 


\section{DISKUSI}

\subsection{Kelebihan dan Kelemahan Website}

Berdasarkan hasil implementasi dari aplikasi yang telah dibuat, website EHS ini memiliki beberapa kelebihan dan kekurangan seperti yang dapat ditunjukkan oleh tabel 1.

Tabel 1. Kelebihan dan Kekurangan Website EHS

\begin{tabular}{|c|c|c|}
\hline No & Kelebihan & Kekurangan \\
\hline 1 & $\begin{array}{l}\text { Semua plugin yang digunakan adalah } \\
\text { open source dan umun digunakan, } \\
\text { sehingga mudah dalam penggunaan. }\end{array}$ & $\begin{array}{l}\text { Source code dalam bentuk kode php, } \\
\text { javascript dan sebagainya sangat mudah } \\
\text { diakses dan dimanipulasi pihak yang tidak } \\
\text { bertanggungjawab apabila didistribusikan } \\
\text { secara bebas. }\end{array}$ \\
\hline 2 & $\begin{array}{l}\text { Cara kerja website secara Real Time, } \\
\text { semua perubahan yang ada dalam } \\
\text { data langsung ditampilkan ke } \\
\text { pengguna. }\end{array}$ & $\begin{array}{l}\text { Jika dilakukan input data pada input murid } \\
\text { dan di submit nanti akan otomatis langsung } \\
\text { masuk pada halaman data murid dan id nya } \\
\text { akan urut meskipun data yang sebelumnya di } \\
\text { hapus maka no id nya akan menggunakan no } \\
\text { id setelahnya data yang sudah di hapus. }\end{array}$ \\
\hline 3 & $\begin{array}{l}\text { Tampilan web yang dinamis dan } \\
\text { sederhana memudahkan pengguna } \\
\text { dalam memahami alur website dan } \\
\text { menemukan informasi yang } \\
\text { dibutuhkan. }\end{array}$ & $\begin{array}{l}\text { Tampilan web pada smartphone belum } \\
\text { responsive dan pada beberapa sistem operasi } \\
\text { smartphone tampilan yang disajikan pada } \\
\text { web ini belum mendukung sehingga } \\
\text { mengakibatkan beberapa fungsi menu tidak } \\
\text { dapat dijalankan. }\end{array}$ \\
\hline
\end{tabular}

\subsection{Hasil Pengujian}

Setelah sistem berhasil dibuat, harus dilakukan pengujian untuk mengetahui keberhasilan dari sistem tersebut[16]. Salah satu pengujian yang dapat dilakukan adalah User Acceptance Testing, yaitu pengujian untuk mengetahui perspektif pengguna terhadap aplikasi yang dibangun[11], [17]. Hasil dari pengujian website yang dilakukan bersama calon pengguna dapat dilihat pada Tabel 2.

Tabel 2. Hasil Pengujian Website

\begin{tabular}{|c|c|c|c|}
\hline No & Pengujian & Hasil & Solusi \\
\hline 1 & $\begin{array}{l}\text { Mengakses } \\
\text { Halaman } \\
\text { Website }\end{array}$ & $\begin{array}{l}\text { Website dapat tampil dengan konten- konten } \\
\text { website yang sesuai dengan strukturnya, } \\
\text { namun ada beberapa penjelasan serta foto } \\
\text { yang belum sepenuhnya terganti karena data } \\
\text { yang kurang dari pemilik EHS }\end{array}$ & $\begin{array}{l}\text { Mengkoreksi kembali tahap coding } \\
\text { pada halaman Home. }\end{array}$ \\
\hline 2 & $\begin{array}{l}\text { Mengelola dan } \\
\text { menampilkan } \\
\text { Data Murid }\end{array}$ & $\begin{array}{l}\text { ID murid muncul dengan urutan dari kecil ke } \\
\text { besar berdasarkan besar angka satu digit paling } \\
\text { akhir pada }\end{array}$ & $\begin{array}{l}\text { Klik beberapa action di samping } \\
\text { kanan untuk mengelola data }\end{array}$ \\
\hline 3 & $\begin{array}{l}\text { Mengelola dan } \\
\text { menampilkan } \\
\text { Data Tutor }\end{array}$ & $\begin{array}{l}\text { Foto tutor seringkali tidak muncul karena } \\
\text { diupload besarnya tidak bisa lebih dari } 2 \mathrm{MB}\end{array}$ & $\begin{array}{l}\text { Reload kembali pada halaman } \\
\text { website agar gambar muncul. } \\
\text { Konversikan foto hingga besarnya } \\
\text { tidak melebihi besar yang } \\
\text { ditentukan sistem serta } \\
\text { mengkoreksi kembali pada tahap } \\
\text { coding halaman data tutor }\end{array}$ \\
\hline 4 & $\begin{array}{l}\text { Mengelola dan } \\
\text { menampikan } \\
\text { Data Pre-post } \\
\text { test }\end{array}$ & $\begin{array}{l}\text { Beberapa file soal bisa di-upload sekaligus } \\
\text { walaupun terkadang menjadikan proses lama }\end{array}$ & $\begin{array}{l}\text { File yang di-upload sekaligus } \\
\text { dibatasi, maksimal } 5 \text { atau } 6 \text { file } \\
\text { saja }\end{array}$ \\
\hline
\end{tabular}

5 Menampilkan Data kehadiran bisa ditampilkan dengan Beri batasan tiap halaman hanya 
Data Pengajar

6 Mengelola dan menampilkan Data

Konfirmasi Pembayaran

7 Mengelola dan menampilkan Data Info benar, namun jika jumlah murid semakin banyak maka akan memerlukan waktu lebih lama untuk mencari ke bagian bawah

Keterangan 'lunas' dibedakan dengan warna background hijau, sedangkan untuk 'belum lunas' dengan warna kuning. Keterangan akan berubah secara otomatis menjadi 'belum lunas' jika waktu sudah mencapai satu bulan. Dan akan berubah menjadi 'lunas' hanya jika dikonfirmasi oleh admin dengan menekan tombol aksi di bagian kanan halaman

Hasil pengumuman mahasantri yang diterima hanya bisa muncul sebanyak 30 pada tabel.
15 nama murid untuk ditampilkan, selebihnya pada halaman selanjutnya

Penyesuaian tanggal untuk mendapatkan waktu satu bulan pada sistem

Load kembali halaman website agar tampil secara keseluruhan.

\section{KESIMPULAN}

Berdasarkan hasil implementasi dan pengujian yang telah dilakukan, dapat diambil kesimpulan bahwa Website yang dibangun memudahkan pengurus Lembaga Kursus Privat Bahasa Inggris 'English Home Soloraya' dalam mendata murid dan pengajar, juga melihat bukti kehadiran murid dan tutor, serta konfirmasi pembayaran.

\section{DAFTAR PUSTAKA}

[1] Y. I. Kurniawan and P. A. Windiasani, "Sistem Pendukung Keputusan Untuk Penentuan Kelolosan Beasiswa Sekolah Menengah Kejuruan (SMK) menggunakan Metode Fuzzy,” J. Tek. Elektro, vol. 9, no. 1, pp. 13-17, 2017, doi: 10.15294/jte.v9i1.9322.

[2] Y. I. Kurniawan and T. I. Barokah, "Klasifikasi Penentuan Pengajuan Kartu Kredit Menggunakan KNearest Neighbor," J. Ilm. Matrik, vol. 22, no. 1, pp. 73-82, 2020, doi: 10.33557/jurnalmatrik.v22i1.843.

[3] F. Y. Al Irsyadi, R. Annas, and Y. I. Kurniawan, "Game Edukasi Pembelajaran Bahasa Inggris untuk Pengenalan Benda-Benda di Rumah bagi Siswa Kelas 4 Sekolah Dasar," J. Teknol. dan Inf., vol. 9, no. 2, pp. 78-92, 2019, doi: 10.34010/jati.v9i2.1844.

[4] F. Y. Al Irsyadi, D. Puspitassari, and Y. I. Kurniawan, “ABAS (Ayo Belajar Sholat): Game Edukasi Pembelajaran Sholat Untuk Anak Tuna Rungu Wicara,” J. Manaj. Inform., vol. 9, no. 1, pp. 17-28, 2019, doi: 10.34010/jamika.v9i1.1537.

[5] F. Y. Al Irsyadi, S. Supriyadi, and Y. I. Kurniawan, "Interactive educational animal identification game for primary schoolchildren with intellectual disability," Int. J. Adv. Trends Comput. Sci. Eng., vol. 8, no. 6, pp. 3058-3064, 2019, doi: 10.30534/ijatcse/2019/64862019.

[6] A. S. Haris, S. Fadli, and A. Tantoni, "Sistem Manajemen Lembaga Penelitian Dan Pengabdian Kepada Masyarakat Berbasis Web," J. Manaj. Inform. dan Sist. Inf., vol. 2, no. 1, pp. 28-35, 2019, doi: 10.36595/misi.v2i1.76.

[7] Y. I. Kurniawan and A. F. S. Kusuma, “Aplikasi Augmented Reality Untuk Pembelajaran Salat Bagi Siswa Sekolah Dasar,” J. Teknol. Inf. dan Ilmu Komput., vol. 8, no. 1, 2021.

[8] F. S. Sulaeman and I. H. Permana, "Sistem Monitoring Penerapan Rencana Anggaran Biaya Berbasis Web," J. IKRA-ITH Teknol., vol. 5, no. 1, pp. 24-31, 2021.

[9] H. Rubedo, H. Suwandi, and S. Mauluddin, "Sistem Informasi Pertanian Berbasis Kecerdasan Buatan," J. Manaj. Inform., vol. 10, no. April, pp. 84-95, 2020, doi: 10.34010/jamika.v10i1.

[10] D. A. Anggoro and Y. E. A. Lukmana, "Sistem Informasi Pengelolaan Data Nilai Siswa Pada Sd Negeri Jambangan 1 Kabupaten Ngawi," Dinamik, vol. 24, no. 2, pp. 102-112, 2019, doi: 10.35315/dinamik.v24i2.7405.

[11] Y. I. Kurniawan, N. Chasanah, and Nofiyati, "Pengembangan Website Informasi Sekolah di SMP Negeri 2 Kalimanah , Purbalingga," J. Solma, vol. 09, no. 02, pp. 335-346, 2020, doi: http://dx.doi.org/10.22236/solma.v9i2.5440.

[12] D. Gunawan, I. A. Ar Raniri, R. N. Setyawan, and Y. D. Prasetya, "Web-Based Library Information System in Madrasah Ibtidaiyah Negeri Surakarta," J. Tek. Inform., vol. 2, no. 1, pp. 33-41, 2021, doi: 10.20884/1.jutif.2021.2.1.44.

[13] Y. I. Kurniawan, A. Fatikasari, M. L. Hidayat, and M. Waluyo, "Prediction For Cooperative Credit Eligibility Using Data Mining Classification With C4.5 Algorithm,” J. Tek. Inform., vol. 2, no. 2, pp. 57-64, 2021, doi: 10.20884/1.jutif.2021.2.2.49.

[14] M. Antaristi and Y. I. Kurniawan, "Aplikasi Klasifikasi Penentuan Pengajuan Kartu Kredit 
Menggunakan Metode Naive Bayes di Bank BNI Syariah Surabaya,” J. Tek. Elektro, vol. 9, no. 2, pp. 45-52, 2017.

[15] A. A. Rahman and Y. I. Kurniawan, "Aplikasi Klasifikasi Penerima Kartu Indonesia Sehat Menggunakan Algoritma Naive Bayes Classifier,” J. Teknol. dan Manaj. Inform., vol. 4, no. 1, 2018.

[16] A. Ahmad and Y. I. Kurniawan, "Sistem Pendukung Keputusan Pemilihan Pegawai Terbaik Menggunakan Simple Additive Weighting," J. Tek. Inform., vol. 1, no. 2, pp. 101-108, 2020, doi: https://doi.org/10.20884/1.jutif.2020.1.2.14.

[17] Y. I. Kurniawan, A. Rahmawati, N. Chasanah, and A. Hanifa, "Application for determining the modality preference of student learning," in Journal of Physics: Conference Series, 2019, vol. 1367, no. 1, pp. 111, doi: 10.1088/1742-6596/1367/1/012011. 